El actual es un momento de cambios en biología evolutiva. La expansión de diversos programas de investigación, las nuevas conexiones entre ámbitos previamente desconectados y la emergencia de nuevas metodologías y preguntas hacen de este período un momento especialmente interesante en la historia de la disciplina. Por ende, la publicación de un libro de evolución en idioma español impone algarabía para la comunidad científica. En su libro titulado "Evolución: El curso de la vida”, el Dr. Milton Gallardo, académico de la Universidad Austral de Chile, nos invita a recorrer los diversos temas de la biología evolutiva desde su prisma personal, forjado a lo largo de años de investigación en tópicos relevantes de la disciplina. El libro, editado por Editorial Médica Panamericana, posee un formato atractivo. Es impreso a color en todas sus partes, posee una separación visual de sus 14 capítulos y cuenta con un glosario de 192 entradas con breves y certeras definiciones de conceptos, un índice analítico, un índice de autores, además de una actualizada bibliografía con 379 referencias al final del volumen. Globalmente, hay muy pocas deficiencias de forma en el escrito. Los errores son menores y principalmente se relacionan con aspectos editoriales, tales como una cierta heterogeneidad en la diagramación de algunas figuras y en la coloración de algunos esquemas y tablas. Sin embargo, todos estos aspectos pueden ser fácilmente subsanados en futuras ediciones de esta obra.

El comunicar y sintetizar el conocimiento acumulado de una disciplina científica en español siempre corre el riesgo inevitable de la redundancia, en el sentido que muchos de los capítulos pueden repetir o refrasear material que ya ha sido desarrollado en la literatura anglosajona. Actualmente existen varios libros de texto en idioma inglés, cada uno con su particular énfasis, que cubren gran parte de lo que pudiera escribirse en español sobre la disciplina. El libro publicado por el Dr. Gallardo, sin embargo, no es estrictamente un libro de texto ya que el escrito se construye marcadamente desde la perspectiva personal del autor, lo cual se advierte fácilmente en los énfasis otorgados a ciertos aspectos de la biología evolutiva por sobre otros. Por ejemplo, mientras la evolución molecular es cubierta en 34 páginas, la evolución cromosómica en 25, la evolución genómica en 34, y la EvoDevo en 40 , otros temas igualmente importantes son cubiertos en un menor número de páginas o no se mencionan en el texto (e.g., genética cuantitativa, estrategias evolutivamente estables, selección sexual). Esta asimetría en los contenidos puede no ser casual sino que probablemente refleja una decisión efectuada a priori por el autor. Con ello se establece un claro criterio de demarcación con libros de texto usados regularmente en clases de pre y postgrado. Este hecho, habla por sí solo de lo interesante de la obra del Dr. Gallardo, quien en la Introducción ya menciona que "Este texto de evolución no aspira a cubrir todos los contenidos que el lector pudiese tener en mente, pero sí pretende diseminar el conocimiento evolutivo actual" (p. 19). En consecuencia, se trata de un libro muy relevante para lectores de habla hispana, que sintetiza la visión de un biólogo con una vasta trayectoria en el estudio de los mecanismos moleculares, genéticos y celulares involucrados en el cambio evolutivo de poblaciones naturales.

La estructura del libro está repartida en 14 capítulos, los cuales son descritos a continuación. Los capítulos 1-2 (20 y 26 páginas, respectivamente) enumeran una serie de hitos claves en la historia del pensamiento evolutivo, poniendo especial énfasis en los fundamentos metodológicos 
y filosóficos de las ideas desde Aristóteles hasta concepciones contemporáneas. Tales concepciones son ilustradas mediante paralelos con los principales eventos históricos que han dado cuenta del despliegue de la diversidad biológica hasta nuestros días. El capítulo aborda lúcidamente las teorías sobre el origen de la vida y sitúa los eventos de diversificación y extinción en escala de tiempo geológica. Aunque por su especialidad, el Dr. Gallardo otorga un mayor énfasis a la evolución de los animales cordados por sobre la evolución de plantas, esto no ocasiona desequilibrio en el capítulo.

E1 capítulo 3 (20 páginas) discute perspectivas desarrolladas en otros dominios de la ciencia (e.g., física, química). La implementación de tales perspectivas a los estudios de biología evolutiva se encuentra actualmente en desarrollo, siendo objeto de debate conceptual desde hace al menos 30 años. El capítulo presenta algunos tópicos (e.g., auto-organización, sistemas complejos, termodinámica en no equilibrio, estructuras disipativas, teoría de hiperciclos, teoría del caos) que no se encuentran en libros de texto sino en textos más especializados, donde se ha sugerido que podrían dar cuenta, al menos en parte, de los fenómenos evolutivos. Estas propuestas tienen en común el hecho que intentan dar cuenta del mismo dominio de fenómenos que la teoría evolutiva ha desarrollado, sólo que a un nivel más general. En otras palabras, la teoría secundaria y menos general (i.e., la teoría evolutiva convencional) sería reducida a la teoría primaria más general (la nueva teoría). Este capítulo, aunque de alguna manera difiere del carácter de la obra en su conjunto, es de gran utilidad para estimular discusiones epistemológicas sobre la pertinencia de estos temas para la biología evolutiva.

Los capítulos 4-5 (15 y 42 páginas, respectivamente) cubren de muy manera excepcional aspectos de evolución a nivel poblacional. Asimismo, se ilustra mediante un interesante ejemplo con roedores Ctenomys los efectos de cuellos de botella demográficos sobre la pérdida de variabilidad genética. Admitiendo que debido al amplio desarrollo conceptual es prácticamente imposible cubrir de manera detallada las ideas más relevantes a este nivel, hay algunas ausencias en el libro que probablemente pueden incluirse en una nueva edición. Por ejemplo, no se presentan el modelo infinitesimal de Fisher para evolución masiva a través de numerosas mutaciones de pequeño efecto y tampoco el modelo balanceado de Wright, elementos esenciales para comprender diferenciación y especiación mediante selección y deriva génica. Algunos avances contemporáneos tales como la aproximación a genes candidatos mediante mapas de ligamiento en loci de gran efecto (QTL) no son mencionados. Por último, formas no Mendelianas de herencia (e.g., interacciones génicas tales como epistasis, efectos de genes complementarios y herencia poligénica, además de herencia citoplasmática y ligada al sexo, entre otros) son conceptos que probablemente ameritan un mayor desarrollo en el escrito.

El capítulo 6 (23 páginas) consiste en revisiones de modelos de especiación e inferencia filogenética. La sección relacionada con modelos de especiación discute los distintos conceptos de especie y formas de aislamiento reproductivo. En el capítulo se cubren de manera muy didáctica e informada los distintos mecanismos no ecológicos de especiación y los patrones de radiación adaptativa resultante en algunos casos. Como apunte para una nueva edición del libro, podría incluirse la regla de Haldane, el fenómeno de esterilidad sesgada por sexo en numerosos grupos de organismos, y la especiación ecológica, modelo que a pesar de haber sido recientemente elaborado, es cada vez más aceptado por las evidencias empíricas que lo avalan.

El capítulo 7 (26 páginas) aborda la inferencia filogenética. La lógica subyacente a la reconstrucción filogenética es presentada de una manera muy didáctica y coherente. Asimismo, los algoritmos y métodos estadísticos son desarrollados de manera muy rigurosa. Sin embargo, a pesar de ser un elemento central para el estudio de la adaptación, no se menciona la lógica del método comparativo ni a los procedimientos de mapeo de caracteres, aspectos que podrían ser incluídos en una nueva edición para proporcionar una visión completa de la perspectiva filogenética al lector. El capítulo 8 (20 páginas) se refieren a los factores que permiten (o dificultan) una clara delimitación de linajes para un 
sistema clasificatorio general. Se ilustra de muy buena manera e informadamente cómo los mecanismos de duplicación genómica y transferencia génica lateral, que al actuar a una velocidad mayor que la evolución por mutación/selección, pueden originar fusiones genómicas e inconsistencias en los sistemas de inferencia filogenética convencionales. Posteriormente, el capítulo 9 (31 páginas) contiene una sección de biogeografía, la que se inicia con una breve descripción de los antecesores y primeros cultores de la disciplina y continúa con definiciones de la tectónica de placas y deriva continental, lo cual permite comprender los cambios históricos ocurridos en la corteza terrestre desde la disgregación del supercontinente Pangea. Hecha esta introducción, se discuten las escuelas dispersalista y de vicarianza para explicar la actual distribución geográfica de los organismos y se ilustra la importancia del método cladista de Hennig para la reconstrucción biogeográfica. Finalmente, se profundiza sobre el impacto de las glaciaciones y del gran intercambio biótico entre Sudamérica y Norteamérica como determinantes de la diversificación de linajes en cada continente, lo cual es tratado de manera didáctica e ilustrada. Finalmente, la teoría de biogeografía de islas y el modelo central de MacArthur y Wilson son tratados de algo marginalmente, lo que sin embargo, no resta interés al capítulo en su totalidad.

Los capítulos que conforman el denominado "triplete molecular", a saber, el capítulo 10 sobre evolución cromosómica (25 páginas), el capítulo 11 sobre evolución molecular (33 páginas) y el capítulo 12 sobre evolución genómica (34 páginas), constituyen un conjunto unitario muy bien hilvanado y provisto de una selección robusta de evidencias. El capítulo 10 desarrolla de manera lúcida los aspectos centrales de la citogenética que a través del análisis de la estructura cromosómica y niveles de ploidía permiten inferir especiación estasipátrida y por poliploidía. La evolución cromosómica cuenta con modelos muy relevantes que dan cuenta de los patrones de aislamiento reproductivo y especiación en diversos taxa, lo cual es presentado de manera sólida y ejemplificado con evidencias de los propios trabajos efectuados por el Dr. Gallardo. El capítulo 11 desarrolla los aportes de la biología molecular al estudio de la evolución. En particular, se describen los aportes de la secuenciación genómica para el entendimiento de diversos fenómenos entre los cuales la duplicación génica se presenta como muy relevante puesto que es posible adscribir la emergencia de novedades evolutivas a este tipo de mecanismos genéticos. La teoría neutral de evolución molecular de Kimura es desarrollada de manera didáctica en este capítulo. Así también se desarrolla la idea del reloj molecular como una herramienta de primera importancia para estimar las tasas de divergencia entre poblaciones y especies. Al final del capítulo el Dr. Gallardo presenta de manera atractiva las consecuencias de los aportes de la biología molecular para concepciones más generales relacionadas con los niveles de evolución, contraponiendo las perspectivas de Dawkins y Gould sobre esta materia. El capítulo 12 desarrolla en mayor profundidad los descubrimientos de duplicaciones genómicas en diversos grupos de organismos. Estos hallazgos permiten analizar críticamente nociones previas de estabilidad en la organización del genoma y así también la concepción de evolución centrada en organismos más que en conglomerados de genes. El capítulo presenta las evidencias actuales relacionadas con el genoma de Paramecium, esponjas, amphioxus, peces, gallina, ornitorrinco, la zarigueya de cola corta, la rata común, ratón, humanos y chimpancé. Tales descripciones, además de su valor intrínseco, permiten evaluar los niveles de similitud y disimilitud de familias génicas y regiones del genoma y así evaluar hipótesis filogenéticas sobre el origen de los grupos (aspecto también tratado en el capítulo 8). Globalmente, este triplete de capítulos se presenta con un mayor nivel de detalle que los capítulos previos, lo cual probablemente obedece a la propia naturaleza de las preguntas y de los objetos de estudio.

El capítulo 13 (40 páginas) desarrolla los recientes avances en biología del desarrollo, macroevolución y EvoDevo. Se trata de un capítulo muy interesante donde se presentan de manera coherente los recientes avances en la disciplina. La información se presenta ordenadamente desde las primeras nociones evolutivas de los biólogos del desarrollo, pasando por la omisión de la biología del 
desarrollo de la teoría evolutiva, hasta los avances más actuales. El autor describe de manera sintética los principales mecanismos epigenéticos tales como metilación, impronta genómica y dominancia nucleolar, poniendo énfasis en la manera en que tales fenómenos pueden inducir cambios en la maquinaria de desarrollo que son heredables, al menos a corto plazo, entre generaciones y que no involucran modificaciones en la estructura del ADN. A continuación, se discuten en detalle los mecanismos de regulación por secuencias no codificantes cis, las que pueden originar profundas modificaciones en el fenotipo de algunos organismos modelo. Las estructuras anatómicas son determinadas en gran parte por un conjunto de familias de genes Hox que participan de manera compleja a través de interruptores moleculares que encienden o apagan cascadas de diferenciación epigenética. En este contexto, el capítulo analiza la función de genes Hox en diversos modelos en un intento por ilustrar su relevancia en la generación de novedades evolutivas. Es así como se describen homologías de distinta naturaleza dependiendo del origen de las similitudes en grupos filogenéticamente alejados. Hacia el final, el capítulo se explaya sobre algunos elementos históricos en la perspectiva EvoDevo y las potenciales consecuencias de expandir la teoría evolutiva hacia ámbitos no considerados previamente. Un aspecto central de esta nueva perspectiva es el reemplazo de modelos de mapeo genotipofenotipo lineales y deterministas por modelos dinámicos y contexto dependientes. Estos últimos modelos contienen fenómenos de asimilación genética y plasticidad del desarrollo en la naturaleza, temas que probablemente capturen un gran interés en el futuro cercano.

El capítulo de cierre (16 páginas) incluye algunos conceptos relacionados con la lógica de la investigación científica, tales como inductivismo, deductivismo y método hipotético-deductivo, para dar luego paso a una discusión sobre creacionismo y diseño inteligente. En esta sección se discute el impacto social de la teoría evolutiva, advirtiendo sobre los peligros de extrapolar directamente los avances en el conocimiento evolutivo a la sociedad humana. Los peligros derivados de la interpretación de algunos fenómenos sociales con elementos de la biología evolutiva, sin hacer las transformaciones pertinentes de los conceptos, son ilustrados con ejemplos de Darwinismo social y sociobiología. Esta sección es especialmente importante para estimular discusiones en estudiantes que recién se acercan al estudio de la biología evolutiva.

Globalmente, el libro es sin lugar a dudas una excelente elección para estudiantes con interés en genética de poblaciones, evolución molecular, genómica y EvoDevo. De igual manera, estudiantes con intereses más alejados de la biología molecular pueden encontrar en sus páginas un valioso material sintetizado que les permitirá ampliar y actualizar su conocimiento de la fenomenología evolutiva en diversos niveles de análisis. El Dr. Gallardo es optimista en que las nuevas herramientas genéticas, moleculares, genómicas y de EvoDevo permitirán desarrollar una nueva síntesis evolutiva, la que actualmente se encontraría en gestación. Aunque las evidencias de estas áreas de investigación no constituyen por ahora un todo articulado que de cuenta integrada de la evolución en los complejos escenarios naturales, la pregunta es si estas aproximaciones confluirán en una revolución Kuhniana o simplemente agregarán conocimiento expandido a la ciencia normal Darwiniana. Probablemente esta pregunta se podrá responder solamente al cabo de unas cuantas décadas. Mientras tanto, y cualquiera sea la respuesta, el esfuerzo de síntesis efectuado por el Dr. Gallardo constituye una importante contribución que clarifica el camino en aquella dirección.

AGRADECIMIENTOS: Agradezco a Patricio Camus por su invitación a escribir esta revisión de libro. Carezza Botto y Marco Méndez efectuaron valiosas sugerencias al escrito. La Sociedad Chilena de Evolución (http://www.socevol.cl) facilitó la publicación de este comentario.

\section{RODRIGO MEDEL}

Departamento de Ciencias Ecológicas, Facultad de Ciencias, Universidad de Chile, Casilla 653, Santiago e-mail: rmedel@uchile.cl 